\title{
Oncological Safety, Surgical Outcome and Patient Satisfaction of Oncoplastic Breast Conserving Surgery with Contralateral Balancing Reduction Mammoplasty
}

\section{Hannah St DK* \\ University of Ottawa, Canada}

*Corresponding author: Hannah St Denis-Katz, University of Ottawa, 190 Melrose Avenue, The Ottawa Hospital, Ottawa Ontario, Canada K1Y 4E9, Tel: 3067152207;

Email: hastdenis@toh.ca

\section{Research Article \\ Volume 3 Issue 2}

Received Date: October 09, 2019

Published Date: November 04, 2019

DOI: $10.23880 /$ ijtps-16000137

\section{Abstract}

Introduction: Oncoplastic breast conserving surgery (OBCS) is considered a cornerstone in the management of locally invasive breast cancer. We evaluated patient reported outcomes of OBCS with contralateral balancing breast reduction mammoplasty and reviewed its oncologic outcomes and complications.

Methods: This is mixed method study design using retrospective chart review and prospective cohort study. Subject underwent OBCS and contralateral balancing breast reduction mammoplasty were enrolled between October 2014 and December 2017. Patient demographics were reviewed. Pre-operative and post-operative outcome and satisfaction was determined using BREAST-QTM, Impact of Events scale, Hospital Anxiety and Depression Scale and Rosenberg self-esteem scale. Outcome measures included clinicopathologic characteristics, complications, margin status, local recurrence, tumor histopathologies, duration of follow-up, patient satisfaction, self-esteem, event related stress and quality of life.

Results: A total of 48 subjects were included in this study. Average age was 56, with a body mass index $29.11 \mathrm{~kg} / \mathrm{m}^{2}$, over a mean follow up of 72.5 weeks. Complete excision with negative margins was obtained in 42 patients (87.5\%), positive margins in 6 patients (12.5\%), all who had re-excision with repeat lumpectomy. No subjects had local recurrence. Thirteen patients developed minor complications, defined as being managed as an outpatient. No patients developed major complications requiring inpatient admission. Patient reported outcomes and satisfaction questionnaires were given to 18 subjects. Post-surgery BREAST-Q ${ }^{\text {TM26 }}$ scores demonstrated improvement in satisfaction with breasts, nipples and sexual well-being. There was a decrease in satisfaction with physical well-being of the chest as well as psychosocial well-being but this was not statistically significant. There was high satisfaction with overall outcome with average score of $80.8 \%$. Women also reported satisfaction with care with average scores of $82.7 \%$ for surgeon, $93.7 \%$ for medical staff and $99.4 \%$ for office staff. For the Rosenberg self-esteem scale, the results were similar for 3- and 12-month postoperative, with an average score of 25.3 and 25.4 respectively; indicating maintenance of normal self-esteem post 


\section{International Journal of Transplantation \& Plastic Surgery}

operatively. The Impact of events scale showed statistically significant difference at 12- post-operative (25.1) when compared to pre-operative scores, pre-operative (41.7) 12 -month post-operative; $p<0.003$. The results indicate that subjects had lower event-related stress. There was no significant change in Hospital Anxiety and Depression Scale.

Conclusion: Our study has shown that the patient who undergo oncoplastic breast conserving surgery (OBCS) have high patient reported outcomes with acceptable oncologic outcomes and complication rates. This is safe, well tolerated and provides good cosmetic outcomes to be performed with contralateral balancing breast reduction mammoplasty.

Level of Evidence: Therapeutic, III.

Keywords: Oncoplastic breast conserving surgery; Breast reduction; Mammoplasty

Abbreviations: BCT: Breast-Conserving Therapy; RCTs: Randomized Controlled Trials; OBCS: Oncoplastic breast conservation surgery; HADS: Hospital Anxiety and Depression Scale; IES: Impact of Events; OBCS: Oncoplastic Breast Conserving Surgery.

\section{Introduction}

Breast reconstruction and the preservation of breast appearance post breast cancer treatment correlates with better psychosocial outcomes [1-4]. Breast-conserving therapy (BCT), which includes wide local excision of the tumor (or lumpectomy) followed by irradiation, has become a standard of care in the management of earlystage invasive breast cancer [4,5]. An important secondary goal is a satisfactory cosmetic outcome as this is associated with both patient satisfaction and improved quality of life [6,7]. Multiple long-term randomized controlled trials (RCTs) have shown survival following BCT to be equivalent to that of mastectomy [8-11]. Although the standard lumpectomy using breast conserving techniques may result in very minor asymmetry, they can also result in large defects that leave the breast distorted. Current literature reports incidence of unfavorable aesthetic results following BCT to affect up to $40 \%$ of patients and has shown to affect patients' psychosocial and quality of life $[4,5,12,13]$. Oncoplastic breast conservation surgery (OBCS) is a type of BCT, which involves combining the latest plastic surgery techniques with breast surgical oncology. When a large lumpectomy is required, the remaining tissue is sculpted to realign the nipple and areola and restore a natural appearance to the breast shape. The contralateral breast is also modified to create symmetry [14-16]. There are three ways this can be achieved, through simple reduction, rearrangement of internal breast parenchymal tissue or replacing by using local or distant flap to reconstruct the defect. Studies in Europe and Asian countries have demonstrated many benefits to immediate oncoplastic reconstruction including single surgery, surgery completion prior to radiation, which decreases the risk of wound healing problems, immediate symmetry of breast after lumpectomy, and relief of symptoms of macromastia [6,17-24]. Despite these benefits there is limited data on outcomes of oncoplastic reconstruction in North America $[4,25]$. The goal of our study was to review patient reported outcomes of OBCS with contralateral balancing breast reduction mammoplasty, complications, oncologic outcomes, and patient satisfaction.

\section{Methods}

This was a mixed method study using retrospective chart review and a prospective cohort study. The study population involved patients 18 years of age or older, who underwent OBCS and contralateral balancing breast reduction mammography with a multidisciplinary approach at the Ottawa Hospital during the period of September 2014 to December 2017. Data collection included retrospective chart review from September 2015 to October 2016. Patients were recruited onwards and data and outcome measures were collected prospectively. Approval from the Ottawa Health Science Network Research Ethics Board was obtained.

Patient demographics included age, BMI, course of disease, past medical history, type of procedure and reduction technique. Outcome measures included clinicopathologic characteristics, complications, margin status, local recurrence, tumor histopathologies, duration of follow-up, patient satisfaction, self-esteem, event related stress and quality of life. 


\section{International Journal of Transplantation \& Plastic Surgery}

Patient reported outcomes and satisfaction were collected using questionnaires, which were given preoperatively, then at 3 month and 12 month postoperatively. The [26] questionnaires included BREAST$\mathrm{Q}^{\mathrm{TM}}$ [26], Rosenburg self-esteem scale [27], Impact of Events scale [28], and Hospital Anxiety and Depression Scale (HADS) [29].

A total scale score of BREAST-QTM was calculated through the QScore scoring software, ranging from 0 to 100 , with a higher score meaning better quality of life or higher satisfaction. Rosenburg self-esteem scale was measured using a 10-item scale that measures global selfworth by measuring both positive and negative feelings about the self. All items are answered using a 4-point Likert scale format ranging from strongly agree to strongly disagree, a score less than 15 may indicate problematic low self-esteem. The Impact of Events (IES) scale is rated on a 5-point scale ranging from 0 ("not at all") to 4 ("often"). The IES scale consists of 15 items, 7 of which measure intrusive symptoms (intrusive thoughts, nightmares, intrusive feelings and imagery), 8 tap avoidance symptoms (numbing of responsiveness, avoidance of feelings, situations, ideas), and combined, provide a total subjective stress score. The scale is intended to be helpful in detecting the effect of the most severe impact events, and those that can leave patients suffering from Post Traumatic Stress Disorder (PTSD). Cut-off point of above 26 is considered moderate or severe impact. The HADS is a fourteen item scale, seven of the items relate to anxiety and seven relate to depression. Each item on the questionnaire is scored from 0-3 and this means that a person can score between 0 and 21 for either anxiety or depression.

\section{Statistical analysis}

We characterized the sample using descriptive statistics. Outcome measures at three different time points (pre-operative, post-operative 3- month and 12month post-operative) were compared using one-way ANOVA with repeated measures and paired sample t-test for two different time points (3-month and 12-month post-operative). Significance level was set at $p<0.05$. Data were expressed as mean and standard deviation for the entire sample.

\section{Results}

During October 2014 to December 2017, a total of 48 subjects underwent oncoplastic breast conserving surgery and contralateral balancing reduction mammoplasty. The mean age was 56 (range, 36 to 83 years), with a body mass index $29.11 \mathrm{~kg} / \mathrm{m}^{2}$ (range, 19.6$42.3 \mathrm{~kg} / \mathrm{m}^{2}$ ), over a mean follow up of 72.5 weeks (range, 1-260 weeks) (Table 1). Complete excision with negative margins was obtained in 42 patients $(87.5 \%)$, positive margins in 6 patients (12.5\%), all who had re-excision with repeat lumpectomy. No subjects had local recurrence. The most common tumor histopathologies were invasive ductal carcinoma $28(58.3 \%)$, followed by ductal carcinoma in situ (DCIS) 8 (16.6\%), and invasive lobular carcinoma 6 (12.5\%).

Grade II and III disease were the most common, 17 $(35.4 \%)$ and $18(37.5 \%)$ respectively.

A total of 43 subjects were administered adjuvant radiation, 35 patients subjects were administered hormonal therapy and 24 subjects were administered adjuvant chemotherapy. (Table 2 )

The mean lumpectomy size weighed $426 \mathrm{~g}$ and reduction size weighed $472 \mathrm{~g}$ with largest size respectively weighing $1090 \mathrm{~g}$ and $1500 \mathrm{~g}$. Most common pedicles for nipple areolar complex were superior medial pedicle $(35.4 \%)$ and inferior pedicle $(35.4 \%)$ on oncoplastic side and superior medial pedicle on the contralateral side $(68.2 \%)$.

Thirteen patients developed minor complications, defined as being managed as an outpatient. No patients developed major complications requiring inpatient admission. Of the minor complications seven (14.5\%) were wound infections treated with outpatient antibiotics. Some of these were diagnosed by ED physician or family physician and a smaller number were diagnosed by primary surgeon. Five $(10.4 \%)$ patients developed seroma that was aspirated as outpatient, and six $(12.5 \%)$ had minor wound dehiscence that were treated with dressings and healed by secondary intention. These complications were immediate post-operative stage prior to the commencement of radiation therapy.

Patient reported outcomes and satisfaction questionnaires were given to 18 subjects. At 3-month post-operative 18 subjects had returned their questionnaires which is a response rate of $100 \%$. At 12 month post-operative 16 subjects returned their questionnaires, a response rate of $83.8 \%$. Our results for BREAST-Q ${ }^{\text {TM26 }}$ demonstrate improvement in satisfaction with breasts, nipples and sexual well-being. There was a 


\section{International Journal of Transplantation \& Plastic Surgery}

decrease in satisfaction with physical well-being of the chest as well as psychosocial well-being but this was not statistically significant; $\mathrm{p}=0.522$ and 0.117 , respectively. There was high satisfaction with overall outcome with average score of $80.8 \%$. Women also reported satisfaction with care with average scores of $82.7 \%$ for surgeon, $93.7 \%$ for medical staff and $99.4 \%$ for office staff (Table $3)$.

For the Rosenberg self-esteem [27] scale, the results were similar for 3- and 12-month post-operative, with an average score of 25.3 and 25.4 respectively; indicating maintain and normal self-esteem post operatively ( $p>0.05$; Table 4). The Impact of events scale [28] showed statistically significant difference at 3 - and 12- postoperative when compared to pre-operative scores, preoperative (41.7) vs. 3-month post-operative (27.2) and 12 -month post-operative $(25.1) ; P<0.003$. The results indicate that subjects had lower event-related stress (Table 4). There was no significant change in Hospital Anxiety and Depression Scale ( $p>0.05$; Table 4$)$.

\begin{tabular}{|c|c|}
\hline Variables & No. of patients (\%) \\
\hline Patients & $48(100)$ \\
\hline \multicolumn{2}{|l|}{ Age, year } \\
\hline Mean & 56 \\
\hline Range & $36-83$ \\
\hline \multicolumn{2}{|l|}{ BMI, $\mathrm{Kg} / \mathrm{m}^{2}$} \\
\hline Average & 29.11 \\
\hline Range & $19.6-42.3$ \\
\hline \multicolumn{2}{|l|}{ Margin Status } \\
\hline Positive & $6(12.5)$ \\
\hline Negative & $42(87.5)$ \\
\hline Smokers & $5(10.41)$ \\
\hline \multicolumn{2}{|l|}{ Co-morbidities } \\
\hline Hypertension & $10(20.83)$ \\
\hline Asthma & $3(6.28)$ \\
\hline Thyroid disease (hypo/hyperthyroidism, goiter) & $6(12.50)$ \\
\hline Hypercholesterolemia & $5(10.41)$ \\
\hline Obesity & $15(31.25)$ \\
\hline Diabetes mellitus & $2(4.16)$ \\
\hline \multicolumn{2}{|l|}{ Stage } \\
\hline I & $3(6.28)$ \\
\hline II & $17(35.4)$ \\
\hline III & $18(37.5)$ \\
\hline IV & $2(4.16)$ \\
\hline I and II & $1(2.08)$ \\
\hline II and III & $1(2.08)$ \\
\hline NA & $4(8.33)$ \\
\hline \multicolumn{2}{|c|}{ Tumor histopathologies } \\
\hline Invasive ductal carcinoma & $28(58.33)$ \\
\hline DCIS & $8(16.66)$ \\
\hline Invasive lobular carcinoma & $6(12.50)$ \\
\hline Invasive mammary carcinoma & $3(6.25)$ \\
\hline Benign Phyllodes tumor & $1(2.08)$ \\
\hline Intraductal papilloma & $1(2.08)$ \\
\hline Pleomorphic LCIS & $1(2.08)$ \\
\hline Local recurrence & 0 \\
\hline Lumpectomy size - documented & $27(56.25)$ \\
\hline
\end{tabular}

Hannah St DK. Oncological Safety, Surgical Outcome and Patient Satisfaction of Oncoplastic Breast Conserving Surgery with Contralateral Balancing Reduction Mammoplasty. Int J Transplant \& Plastic Surg 2019, 3(2): 000137. 


\section{International Journal of Transplantation \& Plastic Surgery}

\begin{tabular}{|c|c|}
\hline Mean & $426 \mathrm{~g}$ \\
\hline Range & $50-1090 \mathrm{~g}$ \\
\hline \multicolumn{1}{|c|}{ Reduction size } \\
\hline Mean & $21(43.75)$ \\
\hline Range & $472 \mathrm{~g}$ \\
\hline $\begin{array}{c}\text { BMI: body mass index; DCIS: ductal carcinoma in situ; } \\
\text { LCIS: Lobular carcinoma in situ; NA: not available }\end{array}$ \\
\hline
\end{tabular}

Table 1: Demographic and clinical characteristics.

\begin{tabular}{|c|c|}
\hline Therapy & No. of patients \\
\hline Neoadjuvant chemotherapy & 8 \\
\hline adjuvant chemotherapy & 24 \\
\hline Neoadjuvant radiation & 0 \\
\hline Adjuvant radiation & 43 \\
\hline Hormonal therapy & 35 \\
\hline
\end{tabular}

Table 2: Summary of Therapy.

\begin{tabular}{|c|c|c|c|}
\hline Items & Pre-operative Score & $\begin{array}{c}\text { Post -Operative 3- } \\
\text { month Score }\end{array}$ & $\begin{array}{c}\text { Post-operative 12-month } \\
\text { Score }\end{array}$ \\
\hline Satisfaction with Breasts & $50.4(18.4)$ & $66.4(25.7)$ & $71.4(19.4)$ \\
\hline Satisfaction with outcome & & $78.4(19.5)$ & $80.8(18.6)$ \\
\hline Psychosocial Well-being & $70.1(18.0)$ & $82.2(20.1)$ & $76.2(18.3)$ \\
\hline Physical Well-being: Chest & $74.1(12.2)$ & $71.3(15.6)$ & $67.2(20.8)$ \\
\hline Sexual Well-being & $47.9(28.8)$ & $63.8(27.9)$ & $55.5(27.6)^{*}$ \\
\hline Satisfaction with nipples & & $75.9(35.2)$ & $80.0(23.3)$ \\
\hline Satisfaction with information & & $73.1(18.4)$ & $73.9(17.5)$ \\
\hline Satisfaction with surgeon & & $82.9(20.2)$ & $82.7(21.3)$ \\
\hline Satisfaction with medical staff & & $91.5(17.5)$ & $93.7(14.9)$ \\
\hline Satisfaction with office staff & & $97.4(11.1)$ & $99.4(2.3)$ \\
\hline \multicolumn{2}{|r|}{} & \\
\hline
\end{tabular}

Table 3: BREAST-Q Questionnaire Scores Mean (Standard Deviation).

\begin{tabular}{|c|c|}
\hline Outcome measures & Mean (SD) \\
\hline Rosenberg self-esteem scale \\
\hline Post -Operative 3-month & $25.3(2.4)$ \\
\hline Post -Operative 12-month & $25.4(1.8)$ \\
\hline Impact of Events scale \\
\hline Pre-operative & $41.7(16.2)$ \\
\hline Post -Operative 3-month & $27.2(15.0)$ \\
\hline Post -Operative 12-month & $25.1(18.7)^{*}$ \\
\hline Hospital Anxiety and Depression scale \\
\hline Pre-operative & $27.8(5.14)$ \\
\hline Post-Operative 3-month & $30.2(8.7)$ \\
\hline Post -Operative 12-month & $29.8(6.8)$ \\
\hline \multicolumn{2}{|c|}{$* \mathbf{p}<\mathbf{0 5}$} \\
\hline
\end{tabular}

Table 4: Patient reported outcomes. 


\section{International Journal of Transplantation \& Plastic Surgery}

\section{Discussion}

Breast conserving therapy is considered a cornerstone in the management of locally invasive breast cancer, aiming to create a breast with a natural shape and symmetry. The patient experience is crucial; key indicators such as patient satisfaction and quality of life have become an important outcome for evaluating the success of OBCS.

In our study, OBCS demonstrated oncological safety comparable to the literature, good patient satisfaction and psychosocial outcomes post operatively. Complete excision with negative margins was obtained in 42 patients $(87.5 \%)$, positive margins in 6 patients $(12.5 \%)$, all who had re-excision with repeat lumpectomy. Breastconserving therapy has become a standard of care in the management of early-stage invasive breast cancer. Women in our study had lower grade disease with grade II and III disease most common, 17 (35.4\%) and 18 (37.5\%) respectively. Patients who undergo OBCS generally have day surgery with low rates of complications. Thirteen patients developed minor complications, defined as being managed as an outpatient. No patients developed major complications requiring inpatient admission. Patients avoid the risk of associated with prosthesis or longer recovery with autologous free flap reconstruction.

Our results for BREAST-Q ${ }^{\mathrm{TM}}$ [26] demonstrate improvement in satisfaction with breasts, nipples and sexual well-being. There was a decrease in satisfaction with physical well-being of the chest as well as psychosocial well-being but this was not statistically significant. This is not surprising as women are at the start of their cancer journey and usually undergo radiation and sometimes chemotherapy following their OBCS. There was high satisfaction with overall outcome with average score of $80.8 \%$. Women also reported satisfaction with care with average scores of $82.7 \%$ for surgeon, $93.7 \%$ for medical staff and $99.4 \%$ for office staff. The Rosenberg self-esteem [27] scores indicated maintenance and normal self-esteem at 3 and 12 month post operatively. The Impact of events scale [28] showed statistically significant difference at $3-$ and 12 - postoperative when compared to pre-operative scores, he results indicate that subjects had lower event-related stress the farther they were out from surgery [29].

There is increasing evidence that OBCS offer patients safe and effective oncological outcomes. In a systematic review, the authors revealed high rates of overall low local recurrence, distant recurrence, positive margin rate, re-excision rate and complication rates, thus endorsing the oncologic safety of OBCS in T1-T2 invasive breast cancer patients [30]. Chakravorty, et al. compared the reexcision and local recurrence rates for OBCS with standard BCS and found that OBCS decreased the rates of both oncological outcomes (2.7\%) [21]. Clough, et al. found that oncoplastic techniques allow larger resections and a recurrence rate of $9 \%$ was reported [14]. Kaur, et al. reported a re-excision rate of $16 \%$ [31], Reitjens, et al. reported local recurrence rate of 3\% [22], Fitoussi, et al. reported a local recurrence rate of 6.8\% [32], and Chauhan, et al. reported no recurrence rate when compared to standard BCS [20].

Many studies have agreed that oncoplastic reconstruction has improved patient satisfaction, psychosocial well-being and quality of life [5,7,13]. A systematic review suggested that patients were satisfied with breast reconstruction whatever the technique was used [1]. A study in USA reported that OBCS increased in the percentage (from $4 \%$ to $15 \%$ ) between 2007 and 2014 of all breast cancer surgeries performed and was accounted for more than $33 \%$ of all breast conservation surgeries [33].

The first international consensus conference on standardization of OBCS was recently published in 2017 [34]. The experts considered OBCS safe and effective for improving aesthetic outcomes. A slim majority believed that OBCS can be used to reduce the rate of positive margins; however, there was consensus that OBCS may increase risk of complications compared to standard BCS. The experts supported the statement that OBCS procedure should be tailored to each individual patient [34].

Timing of contralateral symmetrizing procedures is variable in the literature. In our study, we performed contralateral symmetrizing simultaneously with the breast reconstruction. Similarly, in one study, it was reported that they performed simultaneous contralateral reduction mastopexy in $67 \%$ of OBCS [19].

North America is behind in adopting oncoplastic breast surgery and in training its surgeons to perform breast reconstruction when compared to Europe [3,4,25]. Canada has been slow in its clinical uptake of OBCS compared with the rest of the international community. The majority of breast cancer surgery in Ontario is performed by general surgeons in community hospitals (70\%). General surgeons with no identified subspecialty 


\section{International Journal of Transplantation \& Plastic Surgery}

perform $69 \%$ of breast cancer operations followed by subspecialty breast surgeons and surgical oncologists. A cross-sectional survey of Ontario general surgeons examined the use of oncoplastic techniques in BCS and concluded that lack of training and access to plastic surgeons were considered significant barriers to the adoption of oncoplastic techniques [4].

\section{Conclusion}

Our study has shown that the patient who undergo oncoplastic breast conserving surgery (OBCS) have high patient reported outcomes with acceptable oncologic outcomes and complication rates. This is safe, well tolerated and provides good cosmetic outcomes to be performed with contralateral balancing breast reduction mammoplasty.

\section{References}

1. Guyomard V, Leinster S, Wilkinson M (2007) Systematic review of studies of patients' satisfaction with breast reconstruction after mastectomy. Breast 16(6): 547-567.

2. Kelsall JE, McCulley SJ, Brock L, Akerlund MTE, Macmillan RD (2017) Comparing oncoplastic breast conserving surgery with mastectomy and immediate breast reconstruction: Case-matched patient reported outcomes. J Plast Reconstr Aesthet Surg 70(10): 1377-1385.

3. Peiris L, Olson D, Kelly D (2018) Oncoplastic and reconstructive breast surgery in Canada: breaking new ground in general surgical training. Can J Surg 61(5): 294-299.

4. Maxwell J, Roberts A, Cil T, Somogyi R, Osman F (2016) Current Practices and Barriers to the Integration of Oncoplastic Breast Surgery: A Canadian Perspective. Ann Surg Oncol 23(10): 3259-3265.

5. Campbell EJ, Romics L (2017) Oncological safety and cosmetic outcomes in oncoplastic breast conservation surgery, a review of the best level of evidence literature. Breast Cancer 9: 521-530.

6. Cochrane RA, Valasiadou P, Wilson AR, Al-Ghazal SK, Macmillan RD (2003) Cosmesis and satisfaction after breast-conserving surgery correlates with the

Hannah St DK. Oncological Safety, Surgical Outcome and Patient Satisfaction of Oncoplastic Breast Conserving Surgery with Contralateral Balancing Reduction Mammoplasty. Int J Transplant \& Plastic Surg 2019, 3(2): 000137. percentage of breast volume excised. $\mathrm{Br} \mathrm{J}$ Surg 90(12): 1505-1509.

7. Pirro 0, Mestak 0, Vindigni V, Sukop A, Hromadkova $\mathrm{V}$, et al. (2017) Comparison of Patient-reported Outcomes after Implant Versus Autologous Tissue Breast Reconstruction Using the BREAST-Q. Plast Reconstr Surg Glob Open 5(1): e1217.

8. Jacobson JA, Danforth DN, Cowan KH, d'Angelo T, Steinberg SM, et al. (1995) Ten-year results of a comparison of conservation with mastectomy in the treatment of stage I and II breast cancer. N Engl J Med 332(14): 907-911.

9. Lichter AS, Lippman ME, Danforth DN, d'Angelo T, Steinberg SM, et al. (1992) Mastectomy versus breastconserving therapy in the treatment of stage I and II carcinoma of the breast: a randomized trial at the National Cancer Institute. J Clin Oncol 10(6): 976-983.

10. Poggi MM, Danforth DN, Sciuto LC, Smith SL, Steinberg SM, et al. (2003) Eighteen-year results in the treatment of early breast carcinoma with mastectomy versus breast conservation therapy: the National Cancer Institute Randomized Trial. Cancer 98(4): 697-702.

11. Straus K, Lichter A, Lippman M, Danforth D, Swain S, et al. (1993) Results of the National Cancer Institute early breast cancer trial. J Natl Cancer Inst Monogr (11): 27-32.

12. Haloua MH, Krekel NM, Winters HA, Rietveld DH, Meijer S, et al. (2013) A systematic review of oncoplastic breast-conserving surgery: current weaknesses and future prospects. Ann Surg 257(4): 609-620.

13. Thiessen FEF, Tjalma WAA, Tondu $\mathrm{T}$ (2018) Breast reconstruction after breast conservation therapy for breast cancer. Eur J Obstet Gynecol Reprod Biol 230: 233-238.

14. Clough KB, Lewis JS, Couturaud B, Fitoussi A, Nos C, et al. (2003) Oncoplastic techniques allow extensive resections for breast-conserving therapy of breast carcinomas. Ann Surg 237(1): 26-34.

15. Baildam AD (2002) Oncoplastic surgery of the breast. Br J Surg 89(5): 532-533. 


\section{International Journal of Transplantation \& Plastic Surgery}

16. de Andrade Urban C (2008) New classification for oncoplastic procedures in surgical practice. Breast 17(4): 321-322.

17. van Dongen JA, Voogd AC, Fentiman IS, Legrand C, Sylvester RJ, et al. (2000) Long-term results of a randomized trial comparing breast-conserving therapy with mastectomy: European Organization for Research and Treatment of Cancer 10801 trial. J Natl Cancer Inst 92(14): 1143-1150.

18. Veronesi U, Cascinelli N, Mariani L, Greco M, Saccozzi $\mathrm{R}$, et al. (2002) Twenty-year follow-up of a randomized study comparing breast-conserving surgery with radical mastectomy for early breast cancer. N Engl J Med 347(16): 1227-1232.

19. De Lorenzi F, Hubner G, Rotmensz N, Bagnardi V, Loschi P, et al. (2016) Oncological results of oncoplastic breast-conserving surgery: Long term follow-up of a large series at a single institution: A matched-cohort analysis. Eur J Surg Oncol 42(1): 7177.

20. Chauhan A, Sharma MM, Kumar K (2016) Evaluation of Surgical Outcomes of Oncoplasty Breast Surgery in Locally Advanced Breast Cancer and Comparison with Conventional Breast Conservation Surgery. Indian J Surg Oncol 7(4): 413-419.

21. Chakravorty A, Shrestha AK, Sanmugalingam N, Rapisarda F, Roche N, et al. (2012) How safe is oncoplastic breast conservation? Comparative analysis with standard breast conserving surgery. Eur J Surg Oncol 38(5): 395-398.

22. Rietjens M, Urban CA, Rey PC, Mazzarol G, Maisonneuve P, et al. (2007) Long-term oncological results of breast conservative treatment with oncoplastic surgery. Breast 16(4): 387-395.

23. Shekhawat L, Busheri L, Dixit S, Patel C, Dhar U, et al. (2015) Patient-Reported Outcomes Following Breast Reconstruction Surgery and Therapeutic Mammoplasty: Prospective Evaluation 1 Year PostSurgery with BREAST-Q Questionnaire. Ind J Surg Oncol 6(4): 356-362.

24. Meretoja TJ, Svarvar C, Jahkola TA (2010) Outcome of oncoplastic breast surgery in 90 prospective patients. Am J Surg 200(2): 224-228.

Hannah St DK. Oncological Safety, Surgical Outcome and Patient Satisfaction of Oncoplastic Breast Conserving Surgery with Contralateral Balancing Reduction Mammoplasty. Int J Transplant \& Plastic Surg 2019, 3(2): 000137.
25. Khayat E, Brackstone M, Maxwell J, Hanrahan R, Richardson J, et al. (2017) Training Canadian surgeons in oncoplastic breast surgery: Where do we stand? Can J Surg 60(6): 369-371.

26. Pusic AL, Klassen AF, Scott AM, Klok JA, Cordeiro PG, et al. (2009) Development of a new patient-reported outcome measure for breast surgery: the BREAST-Q. Plast Reconstr Surg 124(2): 345-353.

27. Rosenberg M (1965) Society and the adolescent selfimage. Princeton, NJ: Princeton University Press.

28. Horowitz M, Wilner N, Alvarez W (1979) Impact of Event Scale: a measure of subjective stress. Psychosom Med 41(3): 209-218.

29. Zigmond AS, Snaith RP (1983) The hospital anxiety and depression scale. Acta Psychiatr Scand 67(6): 361-370.

30. De La Cruz L, Blankenship SA, Chatterjee A, Geha R, Nocera N, et al. (2016) Outcomes After Oncoplastic Breast-Conserving Surgery in Breast Cancer Patients: A Systematic Literature Review. Ann Surg Oncol 23(10): 3247-3258.

31. Kaur N, Petit JY, Rietjens M, Maffini F, Luini A, et al. (2005) Comparative study of surgical margins in oncoplastic surgery and quadrantectomy in breast cancer. Ann Surg Oncol 12(7): 539-545.

32. Fitoussi AD, Berry MG, Fama F, Falcou MC, Curnier A, et al. (2010) Oncoplastic breast surgery for cancer: analysis of 540 consecutive cases [outcomes article]. Plast Reconstr Surg 125(2): 454-462.

33. Carter SA, Lyons GR, Kuerer HM, Bassett RL, Oates S, et al. (2016) Operative and Oncologic Outcomes in 9861 Patients with Operable Breast Cancer: SingleInstitution Analysis of Breast Conservation with Oncoplastic Reconstruction. Ann Surg Oncol 23(10): 3190-3198.

34. Weber WP, Soysal SD, El-Tamer M, Sacchini V, Knauer $M$, et al. (2017) First international consensus conference on standardization of oncoplastic breast conserving surgery. Breast Cancer Res Treat 165(1): 139-149. 